\title{
Entanglement of embolised thrombus with an endocardial lead causing pacemaker malfunction and subsequent pulmonary embolism
}

\author{
R A PERRY, D B CLARKE, M F SHIU* \\ From the Departments of Cardiovascular Medicine and ${ }^{\star}$ Cardiothoracic Surgery, Queen Elizabeth Hospital, \\ Edgbaston, Birmingham
}

SUMMARY A 67 year old woman with a permanent pacemaker was admitted with pulmonary 6 oedema and mitral valve incompetence two months after a myocardial infarction. Echo=cardiograms showed good left ventricular function and a large coil of apparent thrombus in thez right atrium prolapsing into the right ventricle. Intermittent loss of pacemaker sensing and cap $\frac{\infty}{\circ}$ ture was noticed on admission and probably caused the supraventricular tachycardia and? ventricular fibrillation that occurred before an exploratory bypass operation. At operation $\overrightarrow{0}$ rupture of the papillary muscle was found and the mitral valve was replaced. A large piece of thrombus was retrieved from the right pulmonary artery. The right heart contained no clot and the pacemaker wire was not displaced.

It is envisaged that the strand of venous thrombus was caught in the permanent pacing wire a the tricuspid valve level resulting in an unusual case of pacemaker malfunction. The eventua $\mathbb{P}_{\mathrm{D}}$ poor outcome was almost certainly influenced by the arrhythmias and pulmonary embolism? caused by the clot and might have been avoided by early operation.

Thromboembolism associated with endocardial pacing leads has been described in many forms. ${ }^{1-3}$ The thrombi usually form in situ, especially around the entry site; they propagate centrally and result in venous obstruction and pulmonary embolism. Serious haemodynamic disturbances, sometimes leading to sudden death, have been described. ${ }^{4}$ We report here a patient with a deep vein thrombus that became entangled with an endocardial pacemaker lead and caused pacemaker failure.

\section{Case report}

A 67 year old woman was admitted with increasing shortness of breath and orthopnoea. A permanent pacemaker had been inserted nine months earlier for complete heart block that was discovered before a hysterectomy operation. The pacemaker was a ventricular demand system which could not be programmed. Two months before the present admission she was treated in another hospital for an inferior myocardial infarction. This was compli-

Requests for reprints to Dr R A Perry, University Department of Cardiovascular Medicine, The Queen Elizabeth Hospital, Queen Elizabeth Medical Centre, Edgbaston, Birmingham B152TH. cated by congestive cardiac failure and mitral regur gitation. Initially, her heart failure had beencontrolled by daily doses of digoxin $0.0625 \mathrm{mg}$, frus emide $80 \mathrm{mg}$, and spironolactone $100 \mathrm{mg}$, with cap topril $12.5 \mathrm{mg}$ three times a day. On examination aiv this admission she was dyspnoeic at rest. The heare. rate was 80 beats $/ \mathrm{min}$ and irregular. The blood pres sure was $110 / 70 \mathrm{~mm} \mathrm{Hg}$ and the jugular venous pressure was elevated by $5 \mathrm{~cm}$. There was an apicaP systolic murmur radiating to the axilla and bilaterab basal rales in the chest. At admission the electro을. cardiogram showed sinus rhythm with atrial and ventricular extrasystoles. Inappropriate pacing artefacts caused by undersensing of the pacemaker sys tem occurred when the patient lay on her right side $N^{\prime}$ There was also evidence of intermittent exit block 2

Chest $x$ ray showed cardiomegaly, pulmonary congestion, and the pacing wire in the normal posi $₫$ tion. She was treated with bed rest and the dose of diuretics was increased. A diagnosis of recent myo cardial infarction was excluded and plans were made्ष to investigate her with a view to mitral valve replace ment. Pacemaker malfunction was unexplained.

Cross sectional echocardiography showed goo left ventricular function. Coincidentally, a sus: 

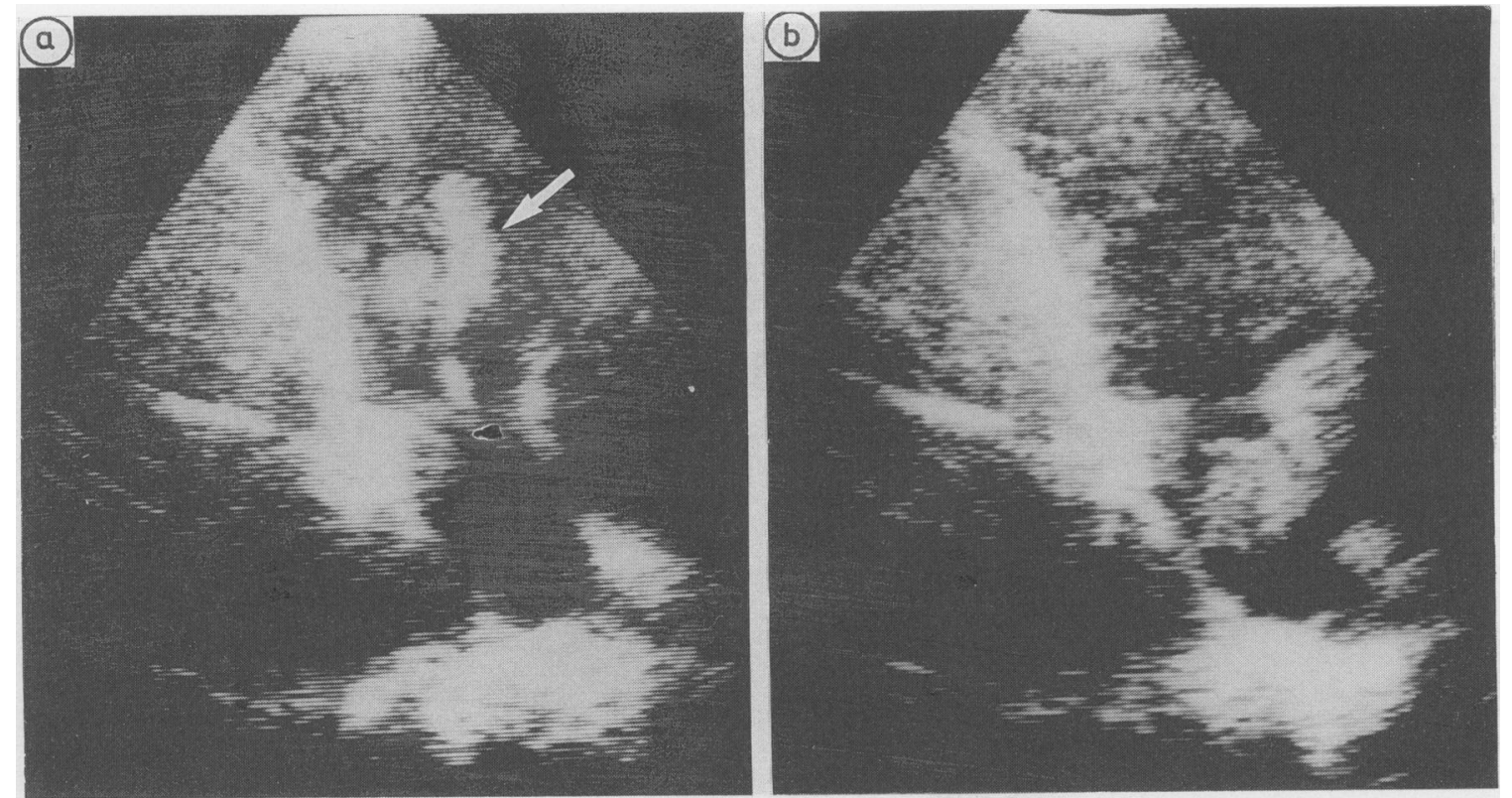

Fig 1 Apical view of cross sectional echocardiograph showing right ventricle containing thrombus (arrowed) round pacing lead in diastole (a) and empty right ventricle with thrombus in right atrium in systole (b).

picious mass was seen prolapsing through the tricuspid valve (fig 1 ). It appeared to be related to the wire, though no points of attachment to the wire or the tricuspid valve could be seen. The features were thought to be consistent with an intracardiac clot or myxoma and right heart catheterisation was avoided. Left heart catheterisation was performed and the left ventricular cineangiogram confirmed severe mitral regurgitation with good overall ventricular function.

A day after admission she had an episode of spontaneous ventricular tachycardia while lying on her right side and the next day ventricular fibrillation developed. This responded to cardiopulmonary resuscitation and DC cardioversion. It was decided that the arrhythmia was due to pacekmaker undersensing. Further episodes were prevented by suppression of the permanent pacemaker with an external pacemaker and skin electrodes. Her general condition deteriorated and the planned mitral valve replacement was brought forward. On the morning of the operation a repeat echocardiogram showed that the right sided echo was normal apart from the presence of an endocardial wire. At operation the right atrium and ventricle were empty and the pacing wire was embedded in the tip of the right ventricle. In view of the echocardiographic findings the pulmonary artery was opened. A $5 \mathrm{~cm}$ by $1.5 \mathrm{~cm}$ thrombus was removed from the right pulmonary artery. Exploration of the left heart showed papillary muscle rupture; mitral valve replacement was carried out as planned.

The sausage shaped thrombus had a smooth ridge in the mid-portion suggesting that this was the site of entanglement with the pacemaker wire (fig 2). The histological appearance of the thrombus was typical of a venous cast of a clot arising from the deep veins.

After operation progressive renal failure developed. The patient had a stroke and died of bronchopneumonia nine days after operation.

\section{Discussion}

There were some salutary lessons to be learned from this case. The predominant cardiac problem was myocardial infarction complicated by papillary muscle rupture causing congestive cardiac failure. Without mitral valve replacement it is unusual for patients with post-infarction rupture of the papillary muscle to survive more than a few days. Some patients have survived for up to three month ${ }^{5}$ with complete papillary muscle rupture as was the case with our patient. With partial rupture the outlook is more favourable with up to $40 \%$ of patients surviving for more than a month. ${ }^{6}$

The preoperative course in this patient was complicated by supraventricular and ventricular arrhythmias induced by pacemaker malfunction. 


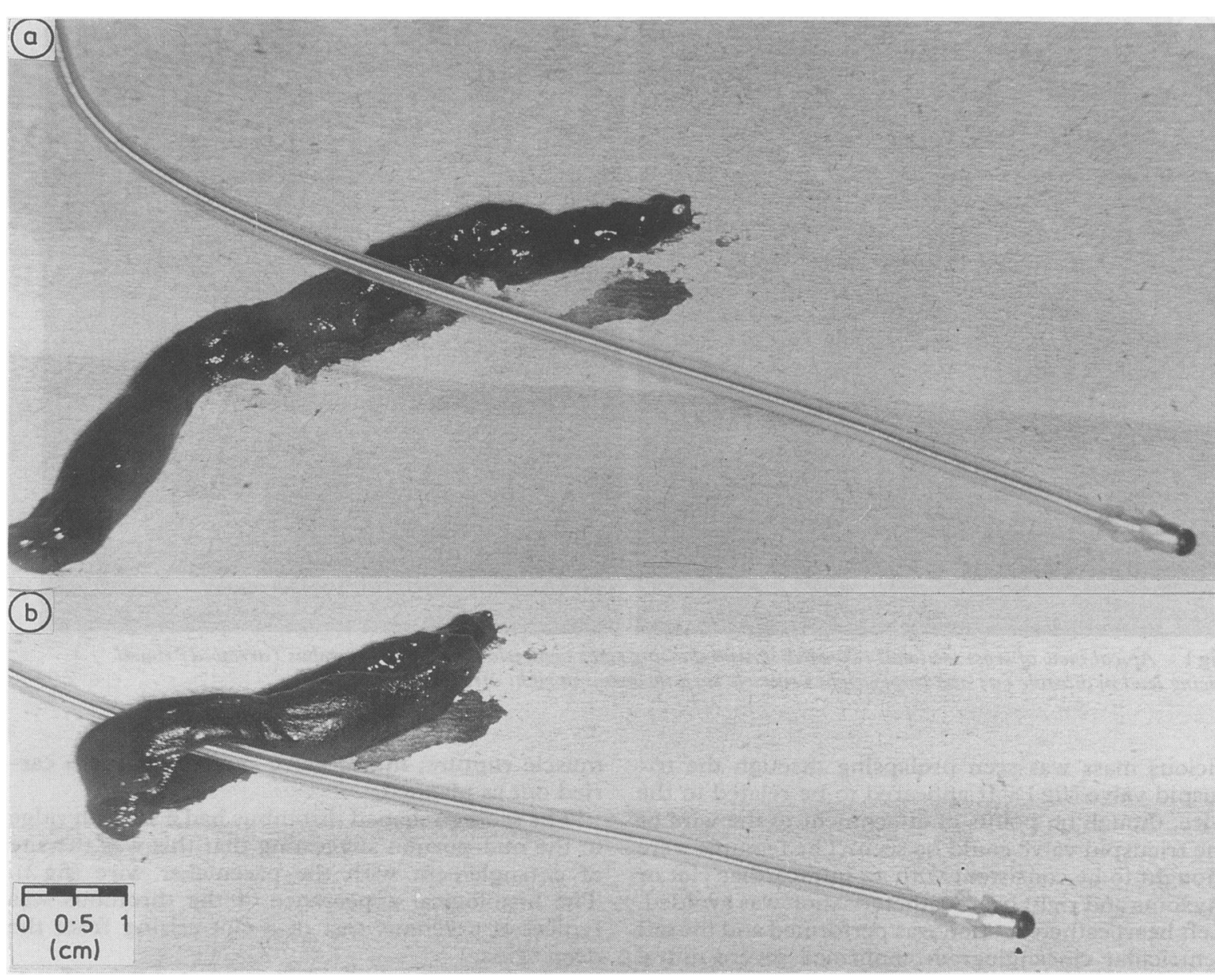

Fig 2 Thrombus removed from right pulmonary artery showing full length (a) and likely association with pacing wire (b).

Subsequent electrical testing of the demand pacemaker showed that it was working normally as was the endocardial lead, which was intact and embedded securely in the apex of the right ventricle. On the basis of our echocardiographic observations we believe that the intermittent pacemaker malfunction, which was clearly related to posture, was due to the pacemaker wire being pulled during systole by the prolapse of the entangled mass (fig 2). The pacemaker was suppressed and the patient had no further arrhythmic events before operation. In the postoperative period the pacemaker functioned normally on demand.

The shape and histology of the thrombus suggest that its source was the deep veins. There have been several reports of the detection by echocardiography of entrapment of thrombi in the right atrium and the tricuspid apparatus. ${ }^{7-10}$ Attempts may be made to remove the thrombus surgically or to allow the thrombus to resolve after treating the patients with anticoagulants. Brown and Anderson have reported reduction in thrombus size and mobility in a patien treated with heparin followed by oral anti ${ }_{0}$ coagulants; however, their patient was too frail for operation. ${ }^{11}$ Come reports a patient who continue to have pulmonary emboli despite treatment with both streptokinase and subsequent heparin. ${ }^{12}$ In $\mathrm{N}$ small series Felner et al showed that despite anti+n coagulation half their patients eventually required surgery for repeated pulmonary emboli from right atrial thrombi. ${ }^{13}$ In one patient, however, resolution occurred without any treatment. In the same paper review of published reports suggested that immedi ate removal of thrombus under cardiopulmonary bypass is the treatment of choice. In none of these cases, however, was the thrombus associated with of pacemaker.

It is difficult to say to what extent the pacemake? 
thrombus contributed to the patient's death. The clinical state deteriorated sharply after an episode of ventricular fibrillation during which cardiopulmonary massage was performed before successful DC cardioversion. If the thrombus had been removed surgically soon after its detection by echocardiography there would have been no risk of its becoming dislodged into the pulmonary circulation during this period of mechanical asystole and physical disturbance. Even if the ventricular fibrillation had been a direct consequence of clot embolisation, early surgery would also have removed this risk.

To our knowledge this is the first report of a sling of embolising clot around an endocardial pacing lead causing pacemaker malfunction and subsequent pulmonary embolism. Although our patient had a potentially lethal condition and post-infarction mitral incompetence, both these additional factors almost certainly contributed to the outcome. The case confirms the usefulness of cross sectional echocardiography in the diagnosis of right sided thrombi. In this case early surgical intervention and removal of the thrombus might have altered the outcome. We believe that in such cases urgent surgical intervention should be considered at an early stage in an effort to avoid pulmonary embolism and its complications. Although right sided thrombi are uncommon and a very rare cause of pacemaker malfunction, cross sectional echocardiography may be useful, as in this case, in instances of otherwise unexplained intermittent pacemaker failure.

\section{References}

1 Haiderer O, Prager H, Koller H, Sterz H. Phlebographic findings after insertion of permanent pace- maker electrodes via the cephalic vein. In: Kumura $\mathrm{E}$, Wathnabe $\mathrm{Y}$, eds. Vth International symposium on cardiac pacing. Tokyo, 1976:5.

2 Mitrovic V, Thormanos J, Schleprer M, Neuss H. Thrombotic complications with pacemakers. Int $\mathcal{f}$ Cardiol 1983;2:363-74.

3 Nicolosi GL, Charmet PA, Zanuttini D. Large right atrial thrombosis: rare complication during permanent transvenous endocardial pacing. $\mathrm{Br}$ Heart $\mathcal{f}$ 1980;43:199-201.

4 Bogart DB, Collins RH, Montgomery MA, Dombek SJ, Earnest JB, Fischer EH. Shock late after implantation of permanent transvenous cardiac pacemaker. Am $\mathcal{F}$ Cardiol 1985;55:1241-2.

5 Wei JY, Hutchins GM, Bulkley BH. Papillary muscle rupture in fatal acute myocardial infarction. Ann Intern Med 1979;90:149-57.

6 Vlodaver Z, Edwards JE. Rupture of ventricular septum or papillary muscle complicating myocardial infarction. Circulation 1977;55:815-24.

7 Rosenzweig MS, Nada NC. Two dimensional echocardiographic detection of circulating right atrial thrombi. Am Heart $\mathcal{F}$ 1982;103:435-6.

8 Starky IR, De Bono DP. Endocardiographic identification of right-sided cardiac intracavitary thromboembolus in massive pulmonary embolism. Circulation 1982;66:1322-5.

9 Shiu MF, Abrams LD. Echocardiographic features of free floating thrombus mimicking right ventricular myxoma. Br Heart $\mathcal{F}$ 1983;49:612-4.

10 Chiarella F, Lupi G, Vecchio C. Early echocardiographic detection of right-sided intracardiac thrombus. Int $\mathcal{F}$ Cardiol 1986;11:121-4.

11 Brown AK, Anderson V. Resolution of right atrial thrombus shown by serial cross sectional echocardiography. Br Heart $\mathcal{F}$ 1985;53:659-61.

12 Come PC. Transient right atrial thrombus during acute myocardial infarction. Am $\mathcal{F}$ Cardiol 1983;51:1228-9.

13 Felner JM, Churchwell AL, Murphy DA. Right atrial thromboemboli: clinical echocardiographic and pathophysiological manifestations. $\mathcal{F}$ Am Coll Cardiol 1984;4:1041-51. 